\title{
Differentials in life expectancy and active life expectancy by socioeconomic status among older adults in Beijing
}

Toshiko Kaneda

Population Council

Zachary Zimmer

Population Council

Zhe Tang

Follow this and additional works at: https://knowledgecommons.popcouncil.org/departments_sbsr-pgy How does access to this work benefit you? Let us know!

\section{Recommended Citation}

Kaneda, Toshiko, Zachary Zimmer, and Zhe Tang. 2004. "Differentials in life expectancy and active life expectancy by socioeconomic status among older adults in Beijing," Policy Research Division Working Paper no. 189. New York: Population Council. 


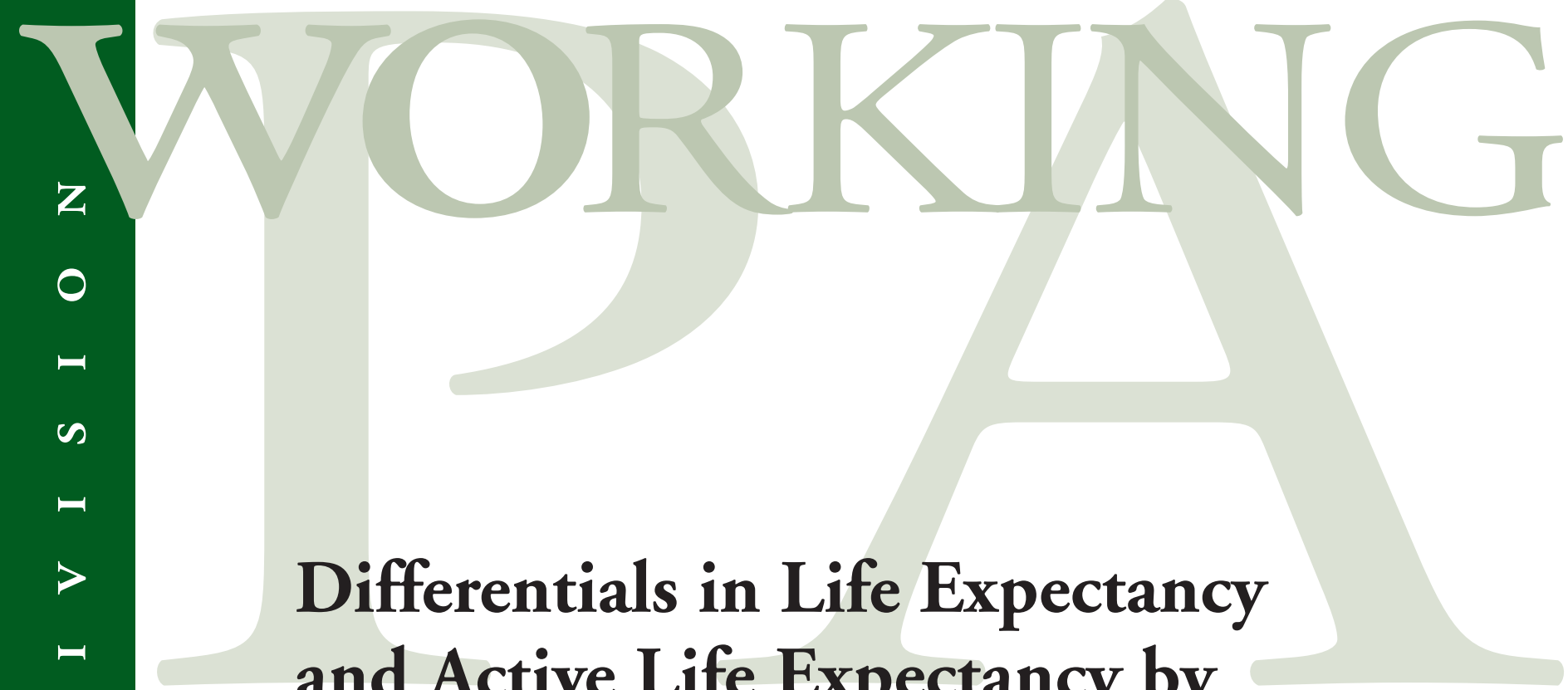

Q and Active Life Expectancy by Socioeconomic Status Among Older Adults in Beijing

Toshiko Kaneda 


\title{
Differentials in Life Expectancy and Active Life Expectancy by Socioeconomic Status Among Older Adults in Beijing
}

\author{
Toshiko Kaneda \\ Zachary Zimmer \\ Zhe Tang
}

Toshiko Kaneda is Berelson Fellow, Population Council. Zachary Zimmer is Associate, Population Council. Zhe Tang is Head and Director of Research, Capital University of Medical Science, Xuanwu Hospital.This research is supported by a grant from the National Institute on Aging entitled "Comparative Study of Aging and Health in Asia," Grant Number R01 AG20063-01.

This material may not be reproduced without written permission from the authors. For a list of Policy Research Division Working Papers, including those available for downloading in PDF format, see www.popcouncil.org/publications/wp/prd/rdwplist.html.

(C) 2004 The Population Council, Inc. 


\begin{abstract}
The study compares estimates of life expectancy and active life expectancy across indicators of socioeconomic status for a cohort of older adults in Beijing Municipality. Our aim is to determine whether associations found are consistent across indicators and with those typically observed in Western industrialized countries. A multistate life table method is used to estimate expected years of total and active life, defined as life spent without limitation in functions necessary for performing daily tasks. We find that men of higher status experience advantages with respect to life and active life expectancies. Among women, only active life expectancy is significantly greater for those of higher status, but the difference by income is not statistically significant. With respect to the proportion of life spent in an active state, both men and women of higher status benefit in comparison to their lower status counterparts. Finally, we find that disparities by socioeconomic status generally increase with age. Despite several inconsistencies across socioeconomic status indicators by sex, findings generally confirm inequalities within a society that is organized very differently socially, economically, and politically from countries in the West.
\end{abstract}


Consistent and robust statistical associations between socioeconomic status and levels of mortality and morbidity have been well-documented for older adults, and reducing such inequality is an important challenge facing populations around the world (National Research Council 2001; Preston and Taubman 1994). Much of the research on these associations has taken place in Western developed countries. The current study examines socioeconomic differentials in life and active life expectancies among older adults in Beijing Municipality, an area encompassing the city of Beijing and its rural environs.

Active life expectancy is a useful measure for summarizing morbidity and mortality experiences and for comparing these across subgroups within populations (Robine and Ritchie 1991). It is obtained through decomposing life expectancy into estimates of time lived in active and inactive states of health - in other words, active life expectancy and inactive life expectancy (ibid.). Estimates can be viewed in absolute terms, that is, the number of years expected to be spent in an active state, or in relative terms, that is, active years as a proportion of total life expectancy (Nusselder 2003). For the current study, we compare these estimates across four indicators of socioeconomic status, namely, three conventional measures of education, income, and occupation and a household-level measure that refers to ownership of household possessions.

China provides a particularly interesting setting to assess the generality of an association between socioeconomic status and health. The country is characterized by a system of stratification that, in theory, promotes more egalitarian access to various resources, and by a history of economic development that differs greatly from that in Western industrialized societies. Despite historically lower levels of economic development and health care expenditures, China has attained a level of life expectancy that is almost comparable to the West, an achievement some have attributed to equalizing access to primary health care (Caldwell 1986). Furthermore, China's population is aging at an unprecedented rate because of drastic declines in fertility triggered in part by the strict family planning policies in place over the last several decades and in part by declining mortality at old age. This makes understanding quantity versus quality of life, that is, the total number of years versus active and healthy years of life among the elderly and across subgroups within the population an important topic for research (Hermalin 1995; Phillips 2000).

\section{Socioeconomic Status, Mortality, ANd Morbidity}

Several classic studies on socioeconomic status differentials in health, such as Kitagawa and Hauser (1973) for the United States and Townsend and Davidson (1982) and Marmot et al. (1987) for the United Kingdom, established that substantial health benefits are associated with higher socioeconomic status. For older populations, it is likely that some selection effects influence the association. That is, those who are apt to be fit and healthy are more likely to survive to old age, potentially muting associations between socioeconomic status and health. Despite this possibility, the association has been confirmed for older populations in a series of more recent studies within several industrialized countries, particularly when health is measured with functional status items 
(Berkman and Gurland 1998; Grundy and Sloggett 2002; Kaplan et al. 1993; Liang et al. 2002; Melzer et al. 2001; Olausson 1991; Ross and Wu 1996; Thorslund and Lundberg 1994; Valkonen 1989; Wolfson et al. 1993).

Previous research has also generally found links between socioeconomic status and life expectancy, active life expectancy, and inactive life expectancy in the West (Bossuyt et al. 2000; Cambois et al. 2001; Crimmins and Saito 2001; Crimmins et al. 1989; Doblhammer and Kytir 1999; Manton et al. 1997; Tu and Kuanjeng 1994; Valkonen et al. 1997). Higher status is associated not only with more years of expected life, but also with enjoying more years in an active state and fewer years in an inactive state. These studies have often shown greater differences by socioeconomic status in active life expectancy than in life expectancy, suggesting that inequalities are most pervasive with respect to quality of remaining life. These studies have also shown that associations persist and even strengthen into very old ages, although part of this may be due to selection. In contrast, no consistent differences in the strength of the associations have emerged by sex (Tu and Kuanjeng 1994). Findings have mostly been based on the Sullivan (1971) method of calculating active life expectancy, which uses cross-sectional data on prevalence rates of health problems.

The magnitude of socioeconomic status differences in life and active life expectancies appears to be influenced by the way in which status and health outcomes are measured (Crimmins and Cambois 2003; Guralnik and Kaplan 1989). This may be due to the fact that specific health outcomes are more readily influenced by factors associated with socioeconomic characteristics or that various socioeconomic status indicators are related to health outcomes through different mediating factors. Income may, for example, be more closely related to access to high-quality medical care or better nutrition, while occupation may be more closely related to health hazards in the work place. Other mediating factors that have been identified include psychosocial factors such as health-related behaviors, stress, social support, and self-efficacy (House et al. 1994; Williams 1990).

Although virtually all studies on the relationship between socioeconomic status and health discussed above have been conducted in Western industrialized societies, some research from Asia is beginning to emerge (Liang et al. 2001; Liang et al. 2000; Tu and Kuanjeng 1994; Zimmer and Amornsirisomboon 2000; Zimmer and Kwong, forthcoming; Zimmer et al. 1998). While these studies have substantiated some of the findings from Western societies, inconsistencies have also materialized. In particular, some indicators of socioeconomic status found to be significant predictors of health in the West are not consistently related to various health outcomes in Asian settings.

\section{Measuring Socioeconomic Status}

There are several issues to consider when measuring socioeconomic status among older populations generally and older populations in developing countries specifically. First, conventional indicators of status may not adequately describe the socioeconomic position of older adults. For instance, income often declines with retirement, and current income for older adults may mask the cumulative effect of economic status throughout 
life (Kaplan et al. 1987). Assigning older adults to occupational categories can be problematic for those who are no longer employed or were never employed, or for those who held multiple jobs over their lifetimes. Use of these categories may be especially inappropriate among older women, who likely have been less attached to the labor force throughout their lifetimes than men.

The problems associated with measures of income and occupation may be amplified in developing countries. For instance, because income for older adults in developing countries typically comes from multiple sources, including monetary assistance from family members and various sideline economic activities, it is difficult to obtain accurate accounts (Hermalin et al. 2002). The common Western concept of occupational standing may be inappropriate in a setting where a large majority work in agricultural occupations, while only a small proportion are found across wide varieties of professional and other nonagricultural occupations.

A second problem is the difficulty in determining the correct causal order between socioeconomic status and health (Smith 1999). Poor health may be a result of poverty and occupational hazards, but it can also force individuals into early retirement and limit their income and occupational options. For this reason, education is often considered to be a more efficacious measure of socioeconomic status than is health status. Information on education is usually available for every adult in any society, and it is fixed relatively early in life and remains constant throughout adulthood (Freedman and Martin 1998; Winkleby et al. 1992). However, in settings with generally low educational attainment, narrow variation in levels of education can limit its power in predicting health outcomes. Moreover, in societies in earlier stages of socioeconomic development or in societies characterized by socialist economic systems, the relationship between education, income, and other indicators of status may be less clear than elsewhere.

Studies that have expanded upon the conventional indicators of socioeconomic status by including alternative indicators, such as financial assets, home or car ownership, and household goods, have shown these indicators to be highly effective in differentiating health status among older adults in the West (Arber and Ginn 1993; Marmot et al. 1987; Robert and House 1996). Studies incorporating these nontraditional measures in developing countries are, however, quite limited. Zimmer and Amornsirisomboon (2000) examined a measure of household amenities in Thailand and found it to be fairly predictive of health outcomes, although they found income to be a stronger predictor.

\section{The BeiJing SetTing}

Before the Communist Party came to power in 1949, China was predominantly agricultural and, even in urban areas, wage labor was not widespread (Harrell 2000). In 1949, the Party took two important steps toward its goal of transforming China into a socialist society. First, it collectivized work and eliminated privately owned businesses, thereby moving production out of the household and into the public sphere (Goldstein and $\mathrm{Ku}$ 1993). Individuals either worked on allocated land in the rural communes or were employed in assigned work-units in urban areas and were paid according to a national wage scale (Davis-Friedmann 1991; Harrell 2000; Parish and Whyte 1978). 
Second, the state demanded that both women and men take part in economic activities outside the household. This step was an attempt to remove preexisting sex differences in wage work and eliminate the norm that women worked inside the home while men worked outside (Harrell 2000).

Among other changes that accompanied the new economic system was the provision of health care. Workers and their dependents in urban areas were generally covered under government and labor insurance programs financed by state enterprises; those in rural areas were covered under a cooperative medical insurance program operated by local collectives (Olson 1993; Shi 1993). Through these programs, almost everyone in China had access to basic health care.

Following the death of the Communist Party Chairman Mao Zedong in 1976, China entered an era of economic reform with policies aimed at moving away from a planned economy (Davis-Friedmann 1991; Harrell 2000; Ikels 1990). Communes were decollectivized and privately owned businesses emerged. China's economy today is often described as a socialist market economy, still made up primarily of the state and collective sectors, yet with an increasing proportion of private-sector activities. Under the current system, China's economy has seen rapid growth. Yet unemployment, which was rare before the reforms, increased and so did the number of bankruptcies among enterprises. Wages, which were kept stable in the past regardless of supply and demand, have also become more unstable. Concurrent changes in health care have come through decentralization of health facilities and health care administration. There have also been declines in health insurance coverage and in the number of primary health care providers, especially in rural areas, and costs for patients have risen sharply (Liu et al. 1995; Shi 1996).

It is unclear how the economic changes of the last five decades have influenced individual-level socioeconomic characteristics and their associations with morbidity and mortality. One might hypothesize that such associations would be weaker among today's elderly, who have spent a large proportion of their adult years living within a system that discouraged differences in socioeconomic status and promoted equal access to health care. Given high rates of labor force participation for both sexes, any association between socioeconomic status and morbidity, and mortality may vary little by sex. However, growing inequalities during the reform era may be strengthening the widely observed associations between socioeconomic status, morbidity, and mortality. Finally, although there is little research on how changes related to health care since the early 1980s have affected the elderly's use of health services or their health status, older adults are likely to be particularly vulnerable to these changes.

\section{METHODS}

Data

Data for our analysis come from the Beijing Multidimensional Longitudinal Study on Aging, a project led by Zhe Tang and his colleagues at the Beijing Municipal Network for Health and Care of the Elderly at the Xuanwu Hospital of the Capital University of Medical Science in Beijing. We use data from the 1992, 1994, and 1997 waves of this 
ongoing study. Three areas within Beijing Municipality are represented in the data collection. The first is Xuanwu district within the city of Beijing. The other two are Daxing, a suburban area, and Huairou, a mountainous area located in the rural suburbs of Beijing. The data are weighted by age and sex based on census figures, so that the weighted sample is representative of the population of these three districts. The sample size is 3,257 , of which women make up 51.1 percent. The average age is 64.8 years for men and 65.2 years for women. Response rates for the three waves of data collection were 90.1 percent, 94.1 percent, and 88.4 percent. Further information on the data can be found in Jiang et al. (2002) and Tang et al. (1999).

\section{Functional limitations}

In each survey wave, respondents were asked to report whether they can perform a series of functional tasks without any help. These included eating, dressing, getting on and off a bed, bathing, walking 300 meters, and walking up and down a flight of stairs. These are all tasks that are necessary for daily functioning and are sometimes referred to as activities of daily living or Nagi functional tasks (Katz et al. 1983; Nagi 1965). We define the "active" state as the ability to perform all six functional tasks without any help. The "inactive" state is defined as requiring some help in performing at least one task. Individuals are coded as being either functionally active or functionally inactive in each of the three waves. In the second and the third waves, individuals may also be coded as having died in the survey interval years, or as having missing data (not responding to the survey or to particular items). Active life expectancy indicates the length of expected life in which one is able to perform all six of these tasks. Inactive life expectancy indicates the length of expected life in which one is unable to perform at least one task.

\section{Socioeconomic status indicators}

We use four indicators of socioeconomic status: education, income, occupation, and household possessions. All are measured at baseline. Because of limited sample size, we dichotomized each indicator in a way that distinguishes those with relatively high status from those with relatively low status. Education is dichotomized as respondents with and without any formal schooling. For income, we first constructed a summary measure by adding income from different sources reported in the survey-for instance, work, pension, and rental income. We then dichotomized the total, with respondents having income above the median level being in the higher status group. Because the levels of income differ greatly by districts, this median level was determined separately for each of the three districts. For occupation, we recognize that the Western conceptualization of prestige is less appropriate to the Chinese setting. Instead, we focus on the physical demands of one's occupation. We dichotomized reported occupation as those whose lifetime work was "white-collar" or light physical labor (considered as the higher status group), versus those in occupations requiring heavy physical labor. Because some adults in our sample report being retired, and some would have had multiple occupations, we used information on occupation that was reported to have been held the longest. 
In contrast to the first three conventional indicators of socioeconomic status, the final indicator is a household-level measure of ownership of selected household possessions, namely, color television, refrigerator, and washing machine. Individuals from households that own all three are coded as being in the higher status group. While other household-level measures, such as home ownership or liquid assets, are more commonly used to indicate household status in other studies, these are not necessarily applicable to the Chinese context. For example, land in Beijing is state-owned (and leased to individuals); thus, there is little option for private home ownership.

We recognize that the division of each measure into higher versus lower socioeconomic status is arbitrary. Several points about these divisions should be made. First, we have attempted to make divisions that make sense within the Chinese context. Second, we have used cut-points that divide the sample fairly evenly. Table 1 shows the percent of individuals coded as having higher status according to each of the four indicators for the total sample and by sex. The fraction in the higher status category is around 40 to 50 percent across the four indicators. There are some appreciable differences by sex in education and income, where the percentages in the higher status groups are around 70 percent for men and around 30 percent for women, while occupation and household possessions show little difference by sex. Third, our goals are to describe general patterns of differences in active life expectancy across relative socioeconomic status categories rather than focus on values of estimates, and to determine whether associations are consistent with those that would be expected on the basis of previous studies.

Table 2 shows the extent to which the socioeconomic status indicators are correlated by presenting concurrence rates, that is, the proportion of individuals who are coded as having higher status or lower status given a combination of two indicators. For example, in our total sample, 66 percent are coded as either having both higher education and higher income or having both lower education and lower income. The results show that the socioeconomic status indicators are strongly correlated for both sexes, but they are also not completely dependent measures.

\section{Analyses}

We estimate life expectancy, active life expectancy, and inactive life expectancy separately by sex, using the IMaCh (Interpolative Markov Chains) software program, a recent innovation in analysis of active life expectancy employing the multistate life table method (Brouard et al. 2002). The program, written by Nicholas Brouard and colleagues at the Institut National d'Etudes Démographiques in Paris, is based on methods for analyzing active life expectancy developed by Laditka and Wolf (1998). The program permits the use of longitudinal datasets when the periods between survey waves are not identical. In our case, first and second survey waves are separated by two years, while the second and third waves are separated by three years. The program also enables us to retain cases with missing data in some waves. IMaCh also generates variance estimates for life expectancy, active life expectancy, and inactive life expectancy, which allows for 
testing statistical significance for differences observed in these estimates across different groups.

The first step in the estimation of active life expectancy is a parameter estimation of transition probabilities between the survey waves using maximum likelihood. Our transition model consists of death as an absorbing state and the states of being functionally active and functionally inactive as two nonabsorbing states, with the possibility of movement between the two nonabsorbing states. There are, thus, three possible transitions from each nonabsorbing state for a total of six transitions between survey waves: from functionally active to functionally inactive, to functionally active, or dead; from functionally inactive to functionally active, to functionally inactive, or dead. These transition probabilities are calculated for all ages (between 55 and $80+$ years), both sexes, and both higher and lower socioeconomic status groups across all socioeconomic status indicators. Then, based on these transition probabilities, we construct multistate life tables for each subgroup, from which we obtain estimates of life expectancy, active life expectancy, and inactive life expectancy.

Since we are primarily interested in comparisons of life expectancy, active life expectancy, and inactive life expectancy between individuals in higher and lower socioeconomic states, we present our main results in the form of a ratio of a given estimate for higher status over the corresponding estimate for lower status at selected ages. For instance, our results for men show that at age 55, those with some education are expected to live 21.9 years compared to 18.3 years for those with no formal education. The ratio of these life expectancies is 1.20 , suggesting that men with some formal education at age 55 are expected to live 20 percent longer than their uneducated counterparts. A ratio above 1.00 indicates a positive relationship between socioeconomic status and the estimate under examination, while a ratio below 1.00 indicates a negative relationship. We focus our discussion on these ratios and on general patterns found in our results rather than highlighting single estimates.

We use variance estimates generated by $\mathrm{IMaCh}$ to test for statistical significance of observed socioeconomic status differentials and report them in our tables. To this end, we first calculate 95 percent and 99 percent confidence intervals around each estimate, then report the socioeconomic status differentials as being significant where confidence intervals do not overlap. Finally, we present the proportion of expected life spent in an active state for each higher and lower status group across all socioeconomic status indicators. This allows for the examination of socioeconomic status differentials in active life expectancy in relative sense.

\section{RESULTS}

Table 3 shows the percent of respondents who are unable to perform each of the six functional tasks without any help as well as the percent unable to perform at least one of the six at baseline by age and sex. In total, 10.5 percent report the inability to perform at least one of the six tasks without help, although the figure differs greatly by age and sex. The percent reporting limitation with at least one task increases with age, as expected, as does the percent reporting limitation with any specific task. For instance, 
about 50 percent of those aged 80 and older compared to only about 3 percent of those aged 55 to 59 report a limitation with at least one task. Women are almost twice as likely as men to report at least one limitation, and this disadvantage exists within virtually all age groups and for all tasks. Looking at individual tasks, more people have difficulty walking up and down stairs than performing other tasks, followed by walking 300 meters, bathing, getting on and off a bed, dressing, and eating. This sequence is quite similar across age groups and for both sexes.

Before introducing socioeconomic status indicators, we present Figure 1 to describe overall patterns of life expectancy, active life expectancy, and inactive life expectancy. The figure graphs years of expected life, active life, and inactive life, as well as the proportion of expected life spent in an active state. For men, both life expectancy and active life expectancy decline steadily with age, as would be expected. In contrast, inactive life expectancy fluctuates little across ages. The proportion of expected life in an active state declines slightly with age, from 0.91 for those aged 55 to 0.75 for those aged 80 .

Patterns are similar for women. Both life expectancy and inactive life expectancy are higher for women than for men at all ages. For instance, at age 55 women can expect to live another 23 years, about four of which are inactive. Men at the same age expect to live 20 years with only about two years in inactive health.

We turn now to the main focus of the current study, namely, the ratios that compare these estimates among respondents of higher status to respondents of lower status across different indicators of socioeconomic status. Table 4 shows ratios for life expectancy, active life expectancy, and inactive life expectancy for each status indicator separately by sex for ages $55,60,65,70,75$, and 80 .

Life expectancy ratios are all greater than 1.00 across all socioeconomic status indicators for all ages and both sexes, indicating that respondents in the higher status groups live longer than do those in the lower status groups. For instance, the first row of the table indicates that, compared to their counterparts in the corresponding lower status groups men aged 55 in the higher education group can expect to live 20 percent longer, those in the higher income group can expect to live 37 percent longer, those in the whitecollar and light physical labor occupation group can expect to live 27 percent longer, and those in the higher household possessions group can expect to live 30 percent longer.

Despite consistency in the direction of the association, the size and the statistical significance of the ratios differ by age and gender. Among men, socioeconomic status differentials in life expectancy ratios are mostly statistically significant and, as noted above, are quite substantial. Ratios increase fairly steadily by age so that by age 80 those of higher status can expect to live 40 percent to 52 percent longer than those of lower status. The life expectancy ratios among women are noticeably smaller across all socioeconomic status indicators and are not generally statistically significant, with the exception of ratios for the household possession measure. Depending upon age and indicator, except for household possessions, women categorized as being of higher socioeconomic status live only 4 percent to 16 percent longer than those of lower status. 
For household possessions, the ratio exceeds 1.20 regardless of age. In contrast to men, no clear age patterns are observed in the life expectancy ratios among women.

Differences in active life expectancy by socioeconomic status are more consistent with expectations for both men and women, although, again, men of higher status are more advantaged than are their female counterparts. All ratios are above 1.00 and, except for income among women, differences tend to be significant, meaning that those in the higher status group can expect to live more active years. Active life expectancy ratios also increase with age for both sexes. For men, depending upon age and status indicator, the advantage ranges from 30 percent to 77 percent. Among women, the ratios are smaller. Except for income, women categorized as being of higher status can expect to live between 20 percent and 73 percent more active years.

The last set of estimates shows the ratios for inactive life expectancy. Patterns here are less clear. While ratios are mostly below 1.00, as expected, many are close to 1.00 , particularly at older ages. Some of the ratios for men are also above 1.00. The exceptions are ratios among women for education and household possessions, which are substantially below 1.00 . None of the ratios, however, is statistically significant, which is likely partly due to the fact that the actual values for inactive life expectancy are quite small and therefore the variances, in relation to the estimates, are large.

Figures 2 and 3 show the proportion of remaining life expected to be lived in an active state for higher and lower status groups. Figure 2 shows the proportions for men and Figure 3 for women. Looking first at Figure 2, the proportion of active life among men is higher for the higher status group across all socioeconomic status indicators. The amount of difference ranges from about 5 to 10 percentage points depending upon the indicator and age. In all cases, the proportion of life spent in an active state decreases with age. At age 55, it is about 90 to 95 percent for those of higher status and 85 to 90 percent for those of lower status. By age 80 , it has decreased to about 80 percent or less for those in the higher status categories and to 70 percent or less for those in the lower categories.

Figure 3 for women shows some consistencies with the results for men. For all indicators, women of higher socioeconomic status can expect to spend more time in an active state regardless of age. But differences are less consistent across indicators, with higher status individuals being relatively more advantaged with respect to education and household possessions, especially compared to the corresponding advantage with respect to income. The proportion of time expected to be lived in an active state is somewhat lower for women than for men, particularly among those in lower socioeconomic status categories, where the proportion of time active can fall to 50 percent at very old ages.

\section{CONCLUSIONS}

We have extended previous research on the association between socioeconomic status and health by examining life expectancy and active life expectancy among older adults living in Beijing Municipality. We focused on ratios of life expectancy, active life expectancy, and inactive life expectancy, contrasting each estimate across categories of higher versus lower status. These ratios were calculated for four measures of 
socioeconomic status, three of which are standard indicators-education, income, and occupation - and one of which is less often used-ownership of household possessions.

Despite large differences in the stage of socioeconomic development and political and economic systems between China and Western industrialized countries, our findings are mostly consistent with findings from the West. We generally find advantages in life expectancy and active life expectancy for older adults categorized as having higher levels of socioeconomic status, especially among men. Consistent with previous findings, we also find starker differences between socioeconomic status groups in active years of life than in total years of life and we find a widening of the gap between the two socioeconomic status groups with increasing age.

Contrary to our expectation, we find none of the socioeconomic status differences in inactive life expectancy to be statistically significant. Although the associations between socioeconomic status and inactive life expectancy are all in the expected direction among women, they are not consistent among men. This lack of significance reflects, in part, the small number of years expected to be spent in an inactive state. However, some of the ratios are close to 1.00 , indicating, in part, little difference in the number of inactive years of life expected between those of higher and lower status. Hence, the result may also reflect circumstances found in China that differ from those found elsewhere, where individuals with higher socioeconomic status tend to live fewer years in an inactive state. It is difficult to speculate on why socioeconomic status characteristics would distinguish active but not inactive years of life. One factor to consider is that older adults in China today, even those of higher status, have spent their childhoods within a relatively unhealthy environment, characterized by high rates of communicable diseases, malnourishment, and other difficult circumstances. Although these older adults may now have an opportunity to extend their life, their earlier disadvantages may result not only in extra years in active states but also some extra years in an inactive state. This situation may change as new cohorts of Chinese, who have lived in relatively healthier environments throughout their lives, begin to age.

Another set of results contrary to expectations involves gender differentials. Despite socialist policies promoting greater gender equality in work, we find that socioeconomic status differences in life expectancy and active life expectancy are greater for men than for women. Furthermore, the specific status indicator made a difference in the results among women while it made little difference among men. Women with the three household possessions had a great advantage over those without, whereas there were smaller differences when using other, individual-level indicators. Income, in particular, was not able to distinguish those women living longer as well as healthier lives. One reason for the gender difference in our findings may be that despite the strong attachment Chinese women have had to the labor market under the communist regime, socioeconomic status indicators such as income do not adequately capture the cumulative effects of economic status for women. Our findings hint at the possibility that women's socioeconomic status may be more closely related to the socioeconomic status of their households than to their own socioeconomic characteristics. Another possibility is that our results reflect gender differences in behaviors that are associated both with 
socioeconomic status and with health outcomes. As one example, prevalence rates for smoking and immoderate drinking in our sample are much lower among women than among men and are also associated with socioeconomic status.

We advise caution when interpreting our results on socioeconomic status differences for several reasons. First, some of these differences may reflect the ways in which specific socioeconomic status indicators were operationalized. Because of sample size limitations, we dichotomized each indicator into a logical division between higher and lower status. This results in admittedly crude divisions. Still, our findings with respect to life and active life expectancies are strong and the patterns that emerge are clear. Indeed, the division of socioeconomic status into basic categories better lends itself to examination of general patterns rather than to estimates for specific years. (We conducted several sensitivity tests by dividing our measures in different ways and the general conclusions remain unchanged.)

Second, we caution against misreading the causal direction of some of these associations. In particular, it may be that those who have better functional health are able to remain employed longer and earn higher incomes at older ages and also are in a better position to purchase household possessions. Yet, when it comes to education and occupation, socioeconomic status is likely to have been determined earlier in life, and the direction of causation from socioeconomic status to health can be more easily assumed.

Third, associations we have presented here do not adjust for possible covariates that might intervene in the association between socioeconomic status and health. Indeed, it is difficult to include many covariates in analyses of active life expectancy, especially if sample sizes are no larger than they are in the current study. We suggest that future research begin to disentangle the mediating factors that provide advantages in life expectancy and active life expectancy for older adults of higher status.

Despite the limitations of our study and several inconsistencies in the results according to socioeconomic status indicators and by sex, the findings generally confirm status inequalities within a society that is organized very differently socially, economically, and politically from countries in the West. In a time of rapid socioeconomic and demographic change in China, it would be highly valuable to monitor both active life expectancy of older adults and its relationship to socioeconomic status over time. Given the population aging taking place, this monitoring will be useful in assessing the needs of older adults within a context of rapid changes in social stratification, social organization, and patterns of old-age mortality. Further examinations of long-term panel data in China would also be useful for determining how trends in morbidity and mortality are being affected by the various social and economic changes taking place. 
Table 1 Percent of Respondents Categorized as Having High Socioeconomic Status by Indicator and Sex

\begin{tabular}{lcccc}
\hline & Education & Income & Occupation & Household possessions \\
\hline Total & 50.0 & 51.2 & 42.9 & 42.8 \\
& & & & \\
Men & 69.6 & 71.1 & 40.2 & 43.4 \\
Women & 30.7 & 31.5 & 45.6 & 42.1 \\
\hline
\end{tabular}

Table 2 Concurrence Rates across Socioeconomic Indicators for the Total Sample, Men, and Women

\begin{tabular}{|c|c|c|c|}
\hline & Education & Income & Occupation \\
\hline \multicolumn{4}{|l|}{ Total Sample } \\
\hline Education & --- & --- & --- \\
\hline Income & .657 & --- & --- \\
\hline Occupation & .679 & .532 & --- \\
\hline Household possessions & .727 & .547 & .782 \\
\hline \multicolumn{4}{|l|}{ Men } \\
\hline Education & --- & --- & --- \\
\hline Income & .653 & --- & --- \\
\hline Occupation & .656 & .540 & --- \\
\hline Household possessions & .669 & .529 & .799 \\
\hline \multicolumn{4}{|l|}{ Women } \\
\hline Education & --- & --- & --- \\
\hline Income & .661 & --- & --- \\
\hline Occupation & .701 & .525 & --- \\
\hline Household possessions & .784 & .566 & .765 \\
\hline
\end{tabular}


Table 3 Percent Reporting Specific Functional Limitations at Baseline (1992) by Age and Sex

\begin{tabular}{|c|c|c|c|c|c|c|c|c|}
\hline & Eating & Dressing & $\begin{array}{r}\text { On/off } \\
\text { Bed }\end{array}$ & Bathing & Walking & $\begin{array}{r}\text { Climbing } \\
\text { Stairs }\end{array}$ & $\begin{array}{r}\text { At Least } \\
\text { One } \\
\text { Limitation }\end{array}$ & Total N \\
\hline \multicolumn{9}{|l|}{ Both Sexes } \\
\hline All ages & 1.3 & 1.7 & 1.8 & 4.9 & 7.7 & 9.5 & 10.5 & 3,257 \\
\hline 55-59 & 0.0 & 0.4 & 0.5 & 1.3 & 2.5 & 2.3 & 2.8 & 1,036 \\
\hline $60-69$ & 1.4 & 1.5 & 1.4 & 3.5 & 5.0 & 5.7 & 6.7 & 1,397 \\
\hline $70-79$ & 1.7 & 3.1 & 2.7 & 8.2 & 13.6 & 18.5 & 20.2 & 644 \\
\hline $80+$ & 6.5 & 6.0 & 8.6 & 24.2 & 37.5 & 47.1 & 50.1 & 180 \\
\hline \multicolumn{9}{|l|}{ Men } \\
\hline All ages & 1.1 & 1.8 & 1.8 & 4.1 & 5.4 & 6.8 & 7.3 & 1,593 \\
\hline $55-59$ & 0.0 & 0.7 & 1.0 & 1.7 & 2.4 & 2.4 & 2.4 & 523 \\
\hline $60-69$ & 1.4 & 1.9 & 1.7 & 3.3 & 3.9 & 4.4 & 4.8 & 687 \\
\hline $70-79$ & 1.6 & 2.8 & 2.1 & 6.9 & 8.8 & 13.3 & 14.5 & 312 \\
\hline $80+$ & 5.2 & 4.3 & 7.5 & 17.6 & 26.8 & 34.5 & 37.4 & 71 \\
\hline \multicolumn{9}{|l|}{ Women } \\
\hline All ages & 1.4 & 1.6 & 1.8 & 5.7 & 10.0 & 12.1 & 13.7 & 1,664 \\
\hline $55-59$ & 0.0 & 0.0 & 0.0 & 1.0 & 2.6 & 2.3 & 3.2 & 513 \\
\hline $60-69$ & 1.3 & 1.0 & 1.2 & 3.8 & 6.2 & 7.1 & 8.6 & 710 \\
\hline $70-79$ & 1.9 & 3.3 & 3.4 & 9.5 & 18.4 & 23.7 & 25.8 & 332 \\
\hline $80+$ & 7.3 & 7.2 & 9.4 & 28.6 & 44.7 & 55.6 & 58.7 & 109 \\
\hline
\end{tabular}


Table 4 Ratios for Life Expectancy, Active Life Expectancy, and Inactive Life Expectancy, Comparing Higher to Lower Status Respondents, by Sex and Selected Ages

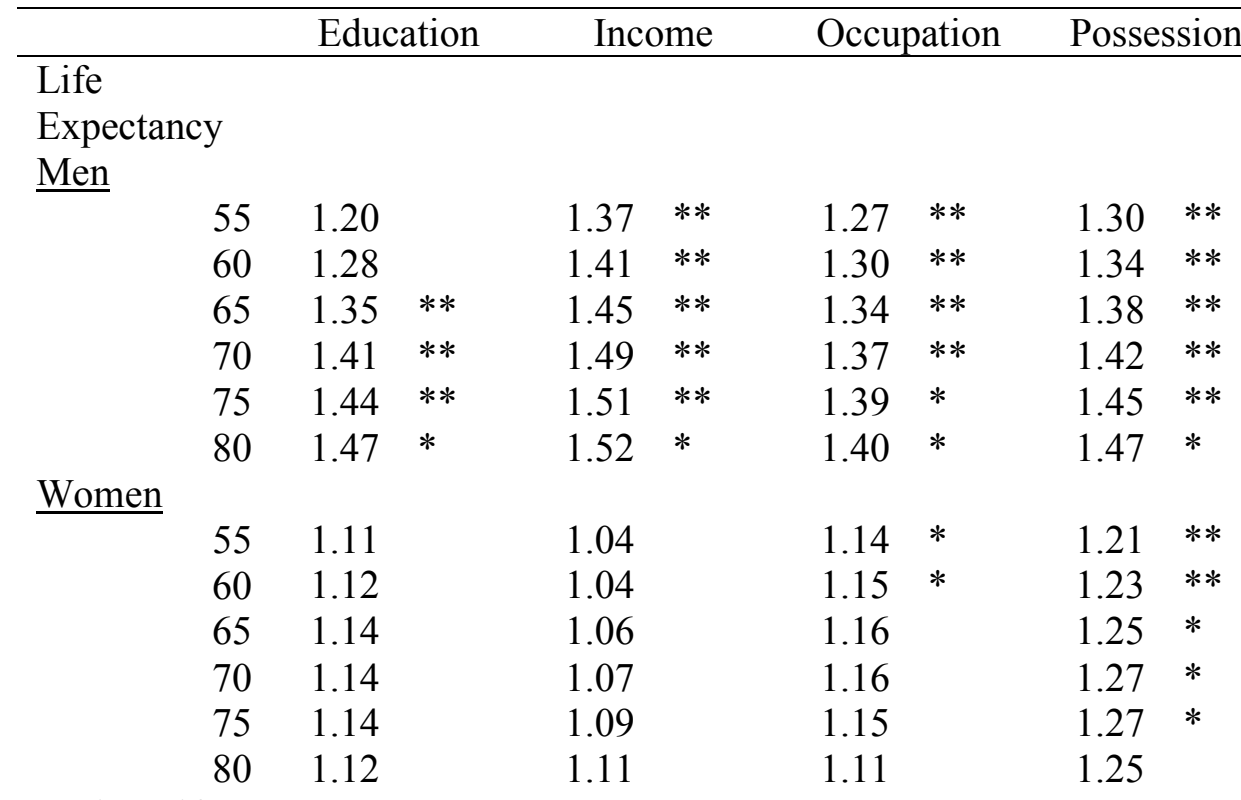

Active Life

Expectancy

Men

Inactive Live

$\begin{array}{lllllllll}55 & 1.30 & * * & 1.44 & * * & 1.32 & * * & 1.34 & * * \\ 60 & 1.37 & * * & 1.51 & * * & 1.37 & * * & 1.40 & * * \\ 65 & 1.44 & * * & 1.57 & * * & 1.42 & * * & 1.45 & * * \\ 70 & 1.50 & * * & 1.64 & * * & 1.48 & * * & 1.52 & * * \\ 75 & 1.57 & * * & 1.71 & * * & 1.55 & * * & 1.58 & * * \\ 80 & 1.63 & * & 1.77 & * & 1.61 & * & 1.64 & *\end{array}$

$\underline{\text { Women }}$

Expectancy

$\begin{array}{llllllll}55 & 1.23 & * & 1.05 & 1.20 & * * & 1.33 & * * \\ 60 & 1.28 & * & 1.07 & 1.24 & * * & 1.39 & * * \\ 65 & 1.33 & * & 1.09 & 1.28 & * * & 1.47 & * * \\ 70 & 1.40 & * & 1.11 & 1.32 & * & 1.56 & * * \\ 75 & 1.48 & * & 1.14 & 1.36 & * & 1.65 & * * \\ 80 & 1.56 & * & 1.19 & 1.35 & & 1.73 & *\end{array}$

$\underline{\text { Men }}$

$\begin{array}{lllll}55 & 0.69 & 0.89 & 0.84 & 0.97 \\ 60 & 0.84 & 0.91 & 0.85 & 0.99 \\ 65 & 0.96 & 0.93 & 0.87 & 1.00 \\ 70 & 1.04 & 0.95 & 0.88 & 1.02 \\ 75 & 1.08 & 0.96 & 0.90 & 1.03 \\ 80 & 1.11 & 0.97 & 0.92 & 1.04\end{array}$

$\underline{\text { Women }}$

\begin{tabular}{lllll}
55 & 0.57 & 0.95 & 0.84 & 0.69 \\
60 & 0.57 & 0.96 & 0.84 & 0.70 \\
65 & 0.58 & 0.97 & 0.84 & 0.71 \\
70 & 0.58 & 0.98 & 0.84 & 0.72 \\
75 & 0.60 & 1.00 & 0.85 & 0.74 \\
80 & 0.62 & 1.02 & 0.87 & 0.76 \\
\hline
\end{tabular}

$* \mathrm{p}<.05 * * \mathrm{p}<.01$ 
Figure 1 Expected Length of Total Life (LE), Active Life (ALE), and Inactive Life (IALE) and Ratio of Active Life Expectancy to Life Expectancy, by Age and Sex
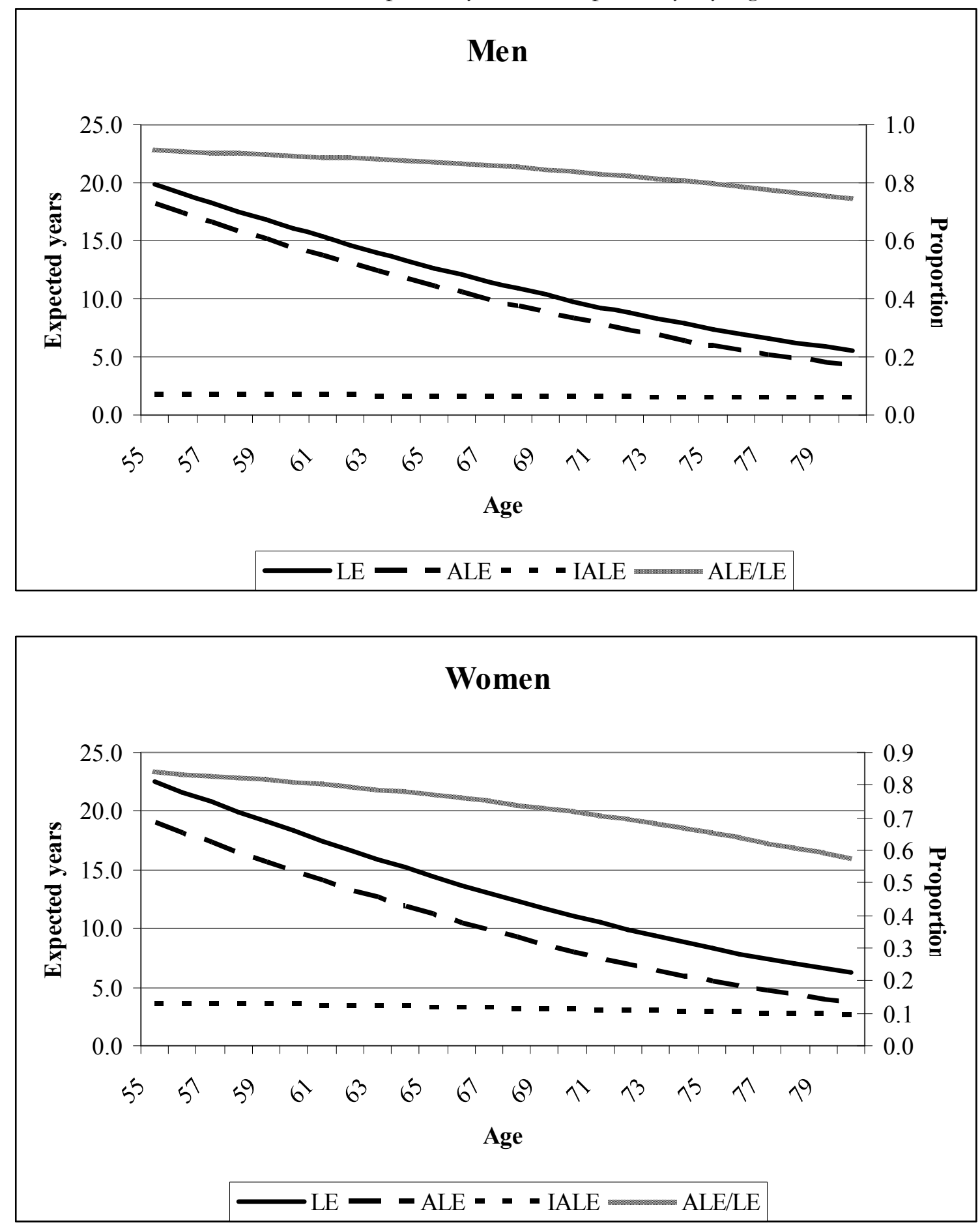
Figure 2 Proportion of Life Expected to be Spent in an Active State, by Men in Higher and Lower Status Groups According to Four Indicators of Socioeconomic Status, by Age
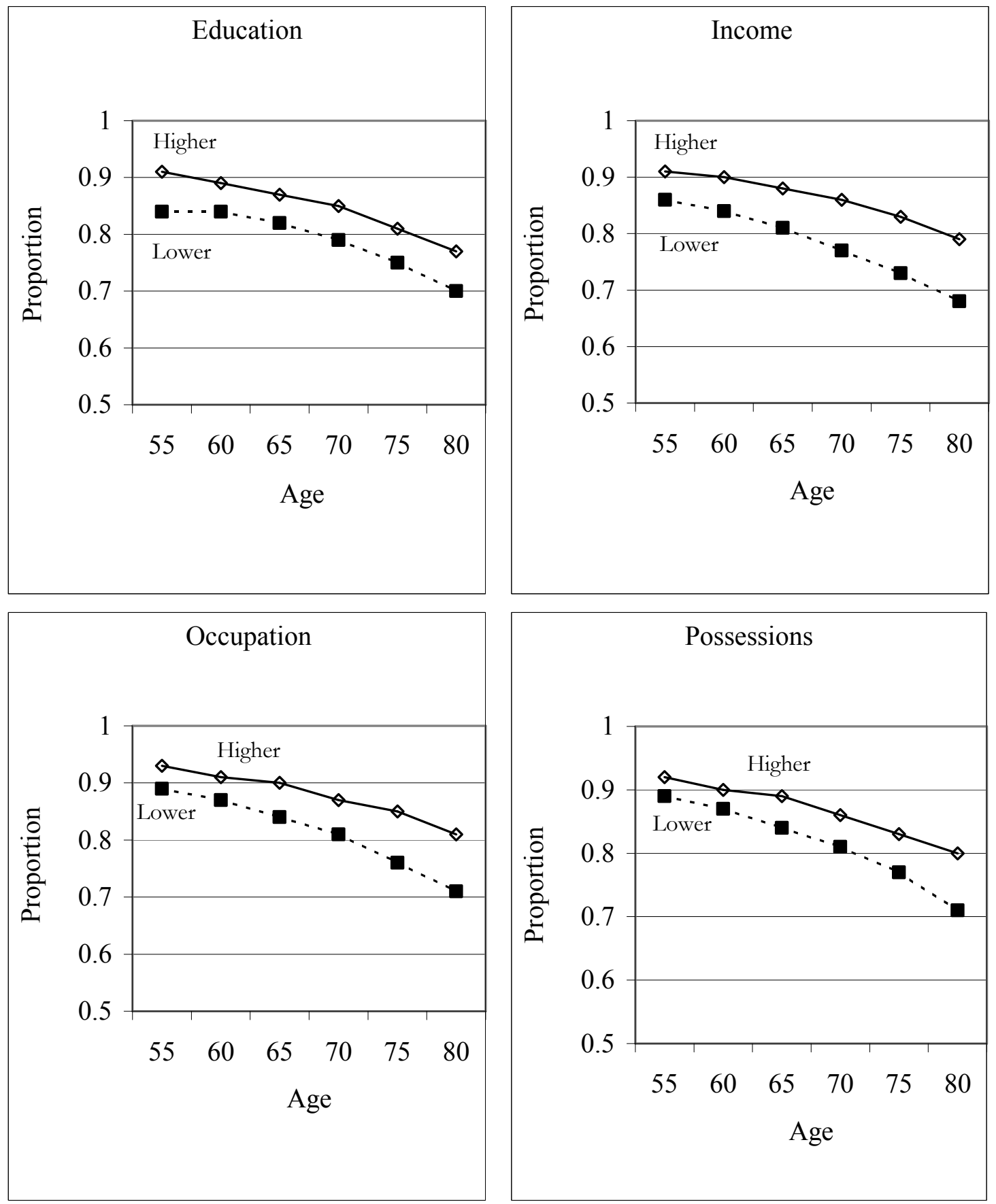
Figure 3 Proportion of Life Expected to be Spent in an Active State, by Women in Higher and Lower Status Groups, According to Four Indicators of Socioeconomic Status, by Age
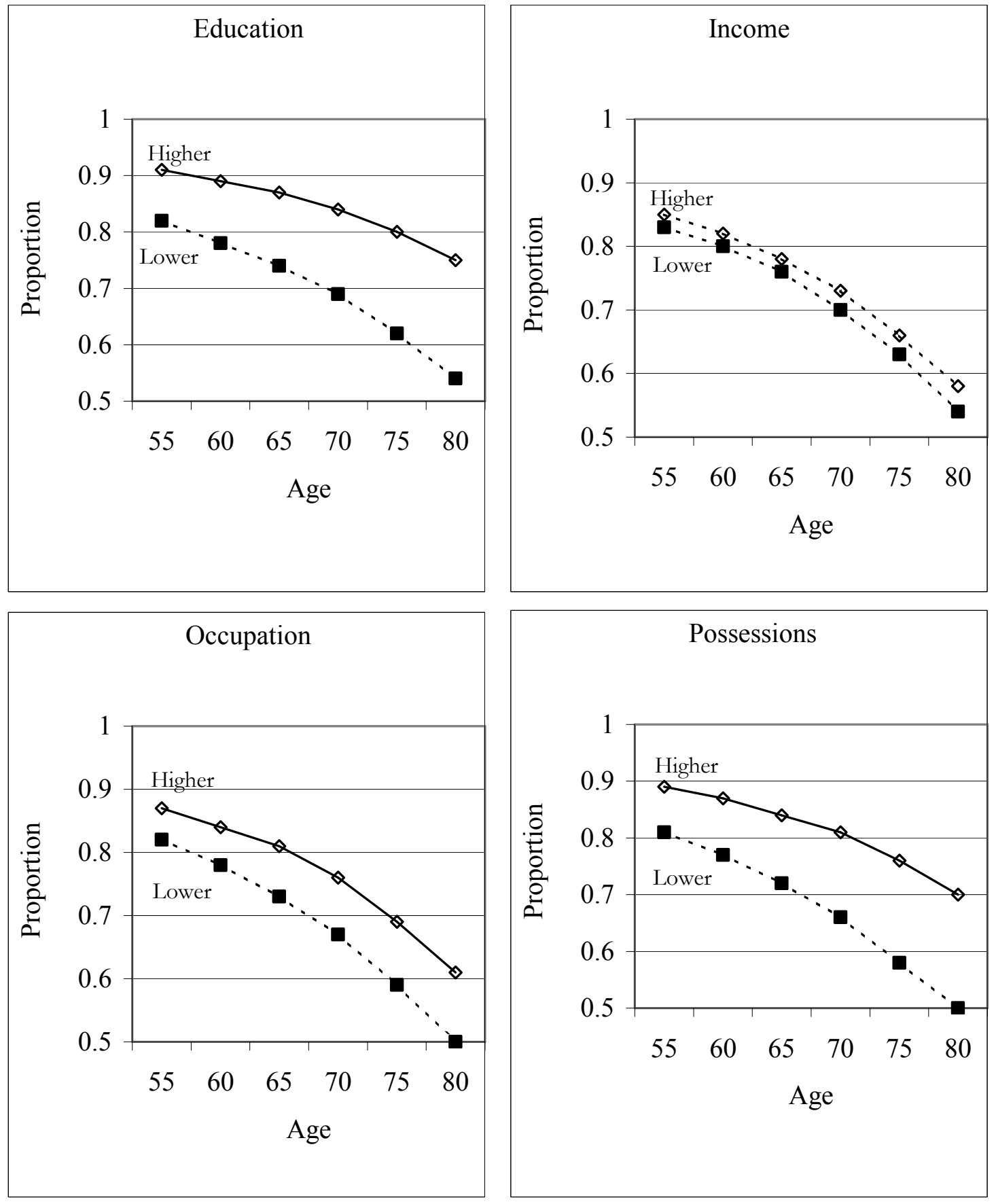


\section{REFERENCES}

Arber, S. and Ginn, J. (1993). Gender and inequalities in health in later life. Social Science and Medicine 36 (1): 33-46.

Berkman, C. S. and Gurland, B. J. (1998). The relationship among income, other socioeconomic indicators, and functional level in older persons. Journal of Aging and Health 10 (1): 81-98.

Bossuyt, N., van Oyen, H. and Page, H. (2000). Healthy life expectancy and disabilityfree life expectancy by educational attainment in Belgium. In Paper Presented at the 12th meeting of REVES.

Brouard, N., Lievere, A. and Heathcote, C. R. (2002). Computing health expectancies using IMaCH: INED and EUROREVES.

Caldwell, J. C. (1986). Routes to low mortality in poor countries. Population Development Review 12(2): 171-220.

Cambois, E., Robine, J. M. and Hayward, M. (2001). Social inequalities in disability-free life expectancy in the French male population, 1980-1991. Demography 38 (4): 513-524.

Crimmins, E. and Saito, Y. (2001). Trends in disability-free life expectancy in the United States, 1970-1990: Gender, racial, and educational differences. Social Science and Medicine 52 (11): 1629-1641.

Crimmins, E., Saito, Y. and Ingegneri, D. (1989). Changes in life expectancy and disability-free life expectancy in the United States. Population and Development Review 15(2): 235-267.

Crimmins, E. M. and Cambois, E. (2003). Social inequalities in health expectancy. In J.M. Robine, C. Jagger, C. D. Mathers, E. M. Crimmins and R. M. Suzman (eds.), Determining Health Expectancies. Chichester, West Sussex, England: John Wiley \& Sons., pp. 111-126.

Davis-Friedmann, D. (1991). Long Lives: Chinese Elderly and the Communist Revolution. Stanford, CA: Stanford University Press.

Doblhammer, G. and Kytir, J. (1999). Social inequalities in mortality and morbidity: Consequences for DFLE. In V. Egidi (ed.), Towards an Integrated System of Indicators to Assess the Health Status of the Population. Rome: ISTAT (Essays No. 4).

Freedman, V. A. and Martin, L. G. (1998). Understanding trends in functional limitations among older Americans. American Journal of Public Health 88 (10): 1457-1462. 
Goldstein, M. C. and Ku, Y. (1993). Income and family support among rural elderly in Zhejiang Province, China. Journal of Cross Cultural Gerontology 8 (3): 197-223.

Grundy, E. and Sloggett, A. (2002). Health inequalities in the older population: The role of personal capital, social resources and socio-economic circumstances. Social Science and Medicine 56 (2003): 935-947.

Guralnik, J. M. and Kaplan, G. A. (1989). Predictors of healthy aging: Prospective evidence from the Alameda County Study. American Journal of Public Health 79 (6): 703-708.

Harrell, S. (2000). The changing meanings of work in China. In B. Entwisle and G. E. Henderson (eds.), Re-drawing Boundaries: Work, Households, and Gender in China. Berkeley: University of California Press., pp. 67-76.

Hermalin, A. I. (1995). Aging in Asia: Setting the research foundation. Asia-Pacific Population Research Reports, No. 4.: Honolulu: East-West Center.

Hermalin, A. I., Chang, M.-C. and Roan, C. (2002). Economic well-being: Insights from multiple measures of income and assets. In A. I. Hermalin (ed.), The Well-Being of the Elderly in Asia: A Four-Country Comparative Study. Ann Arbor, MI: University of Michigan Press., pp. 295-360.

House, J. S., Lepkowski, J. M., Kinney, A. M., Mero, R. P., Kessler, R. C. and Herzog, R. A. (1994). The social stratification of aging and health. Journal of Health and Social Behavior 38 (Sept): 553-578.

Ikels, C. (1990). New options for the urban elderly. In D. Davis and E.F. Vogel (eds.), Chinese Society on the Eve of Tiananmen. Cambridge: Harvard University Press, pp. 215-242.

Jiang, J., Tang, Z., Meng, X. J., and Futatsuka, M. (2002). Demographic determinants for change in activities of daily living: a cohort study of the elderly people in Beijing. Journal of Epidemiology 12: 280-286.

Kaplan, G. A., Seeman, T. E., Cohen, R. D., Knudsen, L. P. and Guralnik, J. (1987). Mortality among the elderly in the Alameda County Study: Behavioral and demographic risk factors. American Journal of Public Health 77 (3): 307-312.

Kaplan, G. A., Strawbridge, W. J., Camacho, T. and Cohen, R. D. (1993). Factors associated with change in physical functioning in the elderly: A six-year prospective study. Journal of Aging and Health 5 (1): 140-153.

Katz, S., Branch, L. G., Branson, M. H., Papsidero, J. A., Beck, J. C. and Greer, D. S. (1983). Active life expectancy. New England Journal of Medicine 309 (20): 12181224. 
Kitagawa, E. M. and Hauser, P. M. (1973). Differential Mortality in the United States: A Study of Socioeconomic Epidemiology. Cambridge: Harvard University Press.

Laditka, S. B. and Wolf, D. A. (1998). New methods for analyzing active life expectancy. Journal of Aging and Health 10 (2): 214-241.

Liang, J., Bennett, J., Krause, N., Kobayashi, E., Kim, H., Brown, J. W., Akiyama, H., Sugisawa, H. and Jain, A. (2002). Old age mortality in Japan: Does the socioeconomic gradient interact with gender and age? Journal of Gerontology: Social Sciences 57 (5): 294-307.

Liang, J., Liu, X. and Gu, S. (2001). Transitions in functional status among older people in Wuhan, China: Socioeconomic differentials. Journal of Clinical Epidemiology 54: 1126-1138.

Liang, J., McCarthy, J. F., Jain, A., Krause, N., Bennett, J. M. and Gu, S. (2000). Socioeconomic gradient in old age mortality in Wuhan, China. Journal of Gerontology: Social Sciences 55B (4): S222-S233.

Liu, H.-C., Lin, K.-N., Teng, E. L., Wang, S.-J., Fuh, L.-L., Guo, N.-W., Chou, P., Hu, H.-H. and Chiang, B. N. (1995). Prevalence and subtypes of dementia in Taiwan: A community survey of 5297 individuals. Journal of the American Geriatrics Society 43: 144-149.

Manton, K. G., Stallard, E. and Corder, L. (1997). Education-specific estimates of life expectancy and age-specific disability in the US elderly population, 1982 to 1991. Journal of Aging and Health (9): 419-450.

Marmot, M., Kogevinas, M. and Elston, M. A. (1987). Social/economic status and disease. Annual Review of Public Health 8: 111-135.

Melzer, D., Izmirlian, G., Leveille, S. G. and Guralnik, J. M. (2001). Educational differences in the prevalence of mobility disability in old age: The dynamics of incidence, mortality, and recovery. Journal of Gerontology: Social Sciences 56B (5): S294-S301.

Nagi, S. Z. (1965). Some conceptual issues in disability and rehabilitation. In M. B. Sussman (ed.), Sociology and Rehabilitation. Washington, DC: American Sociological Association.

National Research Council. (2001). Preparing for an Aging World: The Case for CrossNational Research. Washington, DC: National Academy Press.

Nusselder, W. J. (2003). Compression of morbidity. In J.-M. Robine, C. Jagger, C. D. Mathers, E. M. Crimmins and R. M. Suzman. Determining Health Expectancies Chichester, West Sussex, England: John Wiley \& Sons., pp. 35-58. 
Olausson, P. O. (1991). Mortality among the elderly in Sweden by social class. Social Science and Medicine 32 (4): 437-440.

Olson, P. (1993). Caregiving and long-term health care in the People's Republic of China. Journal of Aging and Social Policy 5 (1-2): 91-110.

Parish, W. L. and Whyte, M. K. (1978). Village and Family in Contemporary China. Chicago: University of Chicago Press.

Phillips, D. R. (2000). Ageing in the Asia-Pacific region: Issues, policies and contexts. In D. R. Phillips (ed.), Ageing in the Asia-Pacific Region: Issues, Policies and Future Trends. New York: Routledge, pp. 1-34.

Preston, S. H. and Taubman, P. (1994). Socioeconomic differences in adult mortality and health status. In L. G. Martin and S. H. Preston (eds.), Demography of Aging. Washington, DC: National Academy Press, pp. 279-318.

Robert, S. and House, J. S. (1996). SES differentials in health by age and alternative indicators of SES. Journal of Aging and Health 8 (3): 359-388.

Robine, J.-M. and Ritchie, K. (1991). Healthy life expectancy: evaluation of global indicator of change in population health. British Medical Journal 302 (February 23): $457-460$.

Ross, C. and Wu, C. (1996). Education, age and the cumulative advantage in health. Journal of Health and Social Behavior 37 (March): 104-120.

Shi, L. (1993). Health care in China: A rural-urban comparison after the socioeconomic reforms. Bulletin of the World Health Organization 71 (6): 723-736.

Shi, L. (1996). Access to care in post-economic reform rural China: Results from a 1994 cross-sectional survey. Journal of Public Health Policy 17 (3): 347-361.

Smith, J. P. (1999). Healthy bodies and thick wallets: The dual relation between health and economic status. Journal of Economic Perspectives 13 (2): 145-166.

Sullivan, D. F. (1971). A single index of mortality and morbidity. American Journal of Public Health 86 (4): 347-354.

Tang, Z., Wang, H.-X., and Meng, X.J. (1999). The prevalence of functional disability in activities of daily living among elderly Beijing Chinese. Archives of Gerontology and Geriatrics 29: 115-125.

Thorslund, M. and Lundberg, O. (1994). Health and inequalities among the oldest old. Journal of Aging and Health 6 (1): 51-69.

Townsend, P. and Davidson, N. (1982). Inequalities in Health: The Black Report. London: Penguin Books. 
Tu, E. J.-C. and Kuanjeng, C. (1994). Changes in active life expectancy in Taiwan: Compression or expansion? Social Science and Medicine 39 (12): 1657-1665.

Valkonen, T. (1989). Adult mortality and level of education: A comparison of six countries. In J. Fox (ed.), Health Inequalities in European Countries Aldershot: Gower.

Valkonen, T., Sihvonen, A-P., and Lahelma, E. (1997). Health expectancy by level of education in Finland. Social Science and Medicine 44: 801-808.

Williams, D. R. (1990). Socioeconomic differentials in health: A review and redirection. Social Psychology Quarterly 53 (2): 81-99.

Winkleby, M. A., Jatulis, D. E., Frank, E. and Fortmann, S. P. (1992). Socioeconomic status and health: How education, income and occupation contribute to risk factors for cardiovascular disease. American Journal of Public Health 82 (6): 816820.

Wolfson, M., Rowe, G., Gentleman, J. E. and Tomiak, M. (1993). Career earnings and death: A longitudinal analysis of older Canadian men. Journal of Gerontology 48 (4): S167-S179.

Zimmer, Z. and Amornsirisomboon, P. (2000). Socioeconomic status and health among older adults in Thailand: An examination using multiple indicators. Social Science and Medicine 52 (8): 1297-1311.

Zimmer, Z. and Kwong, J. (forthcoming). Socioeconomic status and health among older adults in rural and urban China. Journal of Aging and Health.

Zimmer, Z., Liu, X., Hermalin, A. and Chuang, Y.-L. (1998). Educational attainment and transitions in functional status among older Taiwanese. Demography 35 (3): 361375. 


\section{POLICY DIVISION WORKING PAPERS}

If still in print, single copies of up to three working papers from 1989 through 2003 are available free of charge.

Beginning with the 2004 issues, the working papers will no longer be available in print format. Instead they will be distributed electronically. As each new paper is completed subscribers will be notified by e-mail and a link to the paper will be provided.

To subscribe to the Policy Research Division working paper e-mail notification list, or to obtain back issues from 1989 to 2003, please send your request to prdwp@popcouncil.org.

PDFs of recent issues are available at www.popcouncil.org/publications/wp/prd/rdwplist.html

2004

189 Toshiko Kaneda, Zachary

Zimmer, and Zhe Tang, "Differentials in life expectancy and active life expectancy by socioeconomic status among older adults in Beijing."

188 Cynthia B. Lloyd and Monica J. Grant, "Growing up in Pakistan: The separate experiences of males and females."

187 Zachary Zimmer, Xianghua Fang, Toshiko Kaneda, Zhe Tang, and Julia Kwong. "Trends and transitions in children's coresidence with older adults in Beijing municipality."

186 Sajeda Amin and Alaka M. Basu. "Popular perceptions of emerging influences on mortality and longevity in Bangladesh and West Bengal."

185 John Bongaarts. "Population aging and the rising cost of public pensions."
184 Mark R. Montgomery and Paul C. Hewett. "Urban poverty and health in developing countries: Household and neighborhood effects.

2003

183 Agnes R. Quisumbing and Kelly Hallman. "Marriage in transition: Evidence on age, education, and assets from six developing countries."

182 Paul C. Hewett, Barbara S. Mensch, and Annabel S. Erulkar, "Consistency in the reporting of sexual behavior among adolescent girls in Kenya: A comparison of interviewing methods."

181 Zachary Zimmer, Linda G. Martin, and Hui-Sheng Lin, "Determinants of old-age mortality in Taiwan."

\footnotetext{
* No longer available as a printed publication. Download electronic file from Web site only.
} 
180 Frank K. Nyonator, J. Koku Awoonor-Williams, James F. Phillips, Tanya C. Jones, and Robert A. Miller, "The Ghana Community-based Health Planning and Services Initiative: Fostering evidence-based organizational change and development in a resourceconstrained setting."

179 John Bongaarts and Griffith Feeney, "Estimating mean lifetime."

178 Elizabeth F. Jackson, Patricia Akweongo, Evelyn Sakeah, Abraham Hodgson, Rofina Asuru, and James F. Phillips, "Women's denial of having experienced female genital cutting in northern Ghana: Explanatory factors and consequences for analysis of survey data."

177 John Bongaarts, "Completing the fertility transition in the developing world: The role of educational differences and fertility preferences."

176 Cynthia B. Lloyd and Paul C. Hewett, "Primary schooling in sub-Saharan Africa: Recent trends and current challenges."

175 James F. Phillips, Tanya C. Jones, Frank K. Nyonator, and Shruti Ravikumar, "Evidence-based development of health and family planning programs in Bangladesh and Ghana."

174 Geoffrey McNicoll, "Population and development: An introductory view."
173 Paul Demeny, "Population policy: A concise summary."

172 Zachary Zimmer, Napaporn Chayovan, Hui-Sheng Lin, and Josefina Natividad, "How indicators of socioeconomic status relate to physical functioning of older adults in three Asian societies."

171 Sajeda Amin and Nagah H. AlBassusi, "Wage work and marriage: Perspectives of Egyptian working women."

170 Ravai Marindo, Steve Pearson, and John B. Casterline, "Condom use and abstinence among unmarried young people in Zimbabwe: Which strategy, whose agenda?"

169 Zachary Zimmer and Julia Dayton, "The living arrangements of older adults in sub-Saharan Africa in a time of HIV/AIDS."

168 Paul C. Hewett, Annabel S. Erulkar, and Barbara S. Mensch, "The feasibility of computerassisted survey interviewing in Africa: Experience from two rural districts in Kenya."

\section{2}

167* Dominic K. Agyeman and John B. Casterline, "Social organization and reproductive behavior in southern Ghana."

\footnotetext{
* No longer available as a printed publication. Download electronic file from Web site only.
} 
166* Carol E. Kaufman and Stavros E. Stavrou, “' Bus fare, please': The economics of sex and gifts among adolescents in urban South Africa."

165 Kelly Hallman, Agnes R. Quisumbing, Marie Ruel, and Bénédicte de la Brière, "Childcare, mothers' work, and earnings: Findings from the urban slums of Guatemala City."

164 Cynthia B. Lloyd, Cem Mete, and Zeba A. Sathar, "The effect of gender differences in primary school access, type, and quality on the decision to enroll in rural Pakistan."

163 Barbara S. Mensch, Wesley H. Clark, and Dang Nguyen Anh, "Premarital sex in Vietnam: Is the current concern with adolescent reproductive health warranted?"

162 Naomi Rutenberg, Carol E. Kaufman, Kate Macintyre, Lisanne Brown, and Ali Karim, "Pregnant or positive: Adolescent childbearing and HIV risk in South Africa."

161 John Bongaarts, "The end of the fertility transition in the developing world."

160* Julia Dayton and Martha Ainsworth, "The elderly and AIDS: Coping strategies and health consequences in rural Tanzania."
159 Carol E. Kaufman, Shelley Clark, Ntsiki Manzini, and Julian May, "How community structures of time and opportunity shape adolescent sexual behavior in South Africa."

158 Geoffrey McNicoll, "Demographic factors in East Asian regional integration."

157 Zachary Zimmer and Sovan Kiry Kim, "Living arrangements and socio-demographic conditions of older adults in Cambodia."

156 John Bongaarts and Griffith Feeney, "How long do we live?"

155 Zachary Zimmer, Linda G. Martin, and Ming-Cheng Chang, "Changes in functional limitations and survival among the elderly in Taiwan: 1993, 1996, and 1999."

* No longer available as a printed publication. Download electronic file from Web site only. 